\title{
34. Managing time and maintaining focus
}

\section{Colin Hughes}

\section{INTRODUCTION}

In my role at Technological University Dublin (TU Dublin) I have plenty of experience in juggling various projects at any one time. With this project management experience, a professional qualification in the area and experience lecturing the subject, I thought I had the skills required to effectively manage my own doctorate. How wrong I was!

Completing a doctorate has been the most difficult project of my career - but not in the way one might think. While doctoral research requires intensive effort and is a journey often fraught with bouts of uncertainty and self-doubt, the most challenging thing of all for me was managing my time. When I commenced the $\mathrm{PhD}$, I was highly motivated (although my motivation dipped at times) and I set out to complete it in 4 years on a part-time basis. This was perhaps ambitious, you might say it was completely unrealistic, but I had spent 8 months on a proposal, was confident about access to respondents and had previously completed a Master of Philosophy (MPhil), so I wasn't approaching the task with my eyes closed. Almost 7 years on, I have failed miserably on the first of the three goals of project management (Meredith et al., 2017) - time. As I went over time, my employer funding disappeared, so you could say I also failed on the second goal - budget. As I approach my Viva, here's hoping I reach at least one of the goals and that my internal and external examiners feel that my work is within scope, in other words of the required quality!

While I have learned a lot throughout the process and certainly grown as a person, an academic and a researcher, time management has consistently been my Achilles' heel and something that I have worked hard to improve. In reflecting on one's ability to manage time, it is easy to point to the fact that some people simply have busier work roles or have greater responsibilities in their life. While this is undoubtedly true, I 
have learned that time management is far more complex than workload or responsibilities alone and that it is a skillset that can be developed.

From speaking with other part-time doctoral students, I realise that time management is a common challenge. This chapter traces my journey towards effective time management. I begin with a short discussion of my work-life-study balance to set the scene. I then outline my reflections on time management and the changes I have made to overcome a heavy workload and prioritise the things that are important to me. Throughout the chapter I provide suggestions that I hope will help to keep you on track.

\section{SETTING THE SCENE - MY WORK-LIFE-STUDY BALANCE}

When I first commenced my doctoral studies, a colleague told me that a doctorate was a test of endurance, a marathon rather than a sprint. This resonated strongly with me, as I often see work and life 'getting in the way' as part-time students seek to complete their studies. The best-laid study plans are scuppered by issues, events and emergencies of all kinds, and many students require huge levels of endurance to simply get over the finish line. Given the duration of a part-time doctorate, students can face a significant number of challenges, which they must overcome.

At the time of writing this chapter I am: fulfilling a busy role, covering two additional vacant roles, serving on the board of a charity, analysing my data, preparing to deliver two leadership workshops, helping to design a new university campus, and trying to balance a busy home life involving 10-month-old twins, a puppy and an impending house move. This is just a snapshot in the life of a part-time doctoral student. Along with day-to-day work and family life, throughout my studies I have: changed jobs four times, moved universities (when my supervisor got a new job), contributed to numerous conferences, book chapters and newspaper articles, got engaged and married, welcomed twin sons into the world, lost a parent and slept very little!

I imagine that many doctoral students have similar responsibilities and life events to balance. Notwithstanding this, I have no doubt that I would have long finished my doctorate if I had just managed my time more effectively and focused when it mattered. 


\section{REFLECTIONS ON KEY ISSUES}

\section{Issue 1: Failure to Prioritise Tasks}

The nature of my role requires me to balance a wide range of administrative and strategic tasks with multiple requests for information, support and advice. While many of my daily tasks are planned or expected, others are unplanned, often arriving to me in a relentless stream of emails.

For many years I was a slave to my inbox, spending the better part of every day answering a huge volume of emails - the most recent first, in an effort to be as responsive as possible. I began to reflect on this issue. Why was I consumed by email? Why was I trying to be so responsive? I realised that, when I sent emails to others, I didn't expect an immediate response. If they were slow to respond, I simply assumed that they were busy. By responding so quickly, was I simply inviting even more emails?

I thought back to a time management workshop that I completed a few years previously. I still had a poster from this workshop on a wall in my office featuring a four-quadrant time management model - Do it/Date Activate it/Delegate it/Delete it. This approach advocated deleting irrelevant or unwanted emails, doing quick tasks immediately or delegating them to others and then blocking out chunks of time in the diary for larger and more important tasks. The problem was that I wasn't using my diary effectively for the larger tasks. When I sometimes tried to do so, I was not focusing on these tasks at the allocated time. To use Covey's (1989) analogy, I was filling the container (my day) with sand and pebbles (small tasks, mostly replying to emails) and not leaving room for the rocks (the larger urgent tasks that I needed to complete). What I should have been doing was focusing on the important tasks and fitting the other smaller tasks around these. In an effort to keep on top of my workload, I ended up bringing my rocks home in the evening or at weekends. This became the norm and while impacting family life, it also made doctorate progress almost impossible.

So I began to use my diary more effectively. However, I was still struggling to shift my focus from email. Tidying up my inbox was a relatively easy way to start the day, especially if I hadn't slept well (mainly due to working late on rocks!). Also, clearing off tasks first thing in the morning gave me a sense of satisfaction and a feeling that I was being productive.

Time management commentators often advocate not turning on email first thing in the morning, but rather tackling an important task first. 
However, I usually had the information I required to work on tasks saved within emails. Once the email was switched on, something urgent (for someone else) popped up and took precedence over my planned tasks. Therefore, I started to download or create a file before leaving work each evening that allowed me to focus on an important task the next morning. Admittedly, I still have to fight the automatic impulse, built up over 15+ years, of turning on email first thing in the morning. In order to keep one's head out of the email space, it is also important not to check email on one's phone over breakfast or on the way to the office. I have to admit that I have found it incredibly difficult to fight this impulse and I sometimes slip back into bad habits.

I now diary larger tasks and begin each day by completing an important task. This replaces the previous satisfaction of partially clearing my inbox. I find that I manage to fit in email responses or phone calls around these larger tasks. When an email requires an action that takes some time, I will schedule time for it, tell the person(s) concerned that I am extremely busy and give them a realistic response date. I also try to keep one or two days in the week free of meetings so that I can get a clear run on larger tasks. What does all of this mean for my doctoral studies? Well, now I am far less likely to bring work home and I can use evenings and weekends to work on my doctorate rocks and family rocks, thus creating a much nicer balance.

\section{Issue 2: Being Afraid to Say 'No' or 'Not Right Now'}

This might sound unhelpful to some, but let me explain. Since commencing my doctorate, I have blocked out a lot of time in the diary for study, only to add meetings and larger tasks (requiring more than an email response) as the requests arrived in my inbox, by phone or in person. While some of these requests were from senior people or were emergencies and therefore non-negotiable, others could have been refused or pushed out a week or two.

It has taken me some time to realise that one can be over-helpful at the expense of one's own effectiveness and well-being. I am naturally a conscientious person and always willing to help people out. However, I have been overly eager to help with other people's urgent issues above my own. For many years, this put me under huge pressure to then complete my own tasks, again heightening the level of evening and weekend work at a cost to my own family life and notably to my doctorate progress. I have learned that a balance needs to be struck between being responsive and focusing on one's own priorities. As such, it is important to be comfortable saying 'No' or 'Not right now'. This can 
be particularly relevant for managers; as Oncken and Wass (1974) advise, managers must not take ownership for employees' tasks. Rather, employees should be encouraged to work through issues themselves with support from their manager. I have been very guilty of taking on multiple tasks at any one time in an effort to be helpful and I now realise that people benefit more from autonomy, taking control of their own issues and upskilling in the process.

So now I am more comfortable with saying no to a request or suggesting a future time when I can help. The first time I said no to a request (helping someone with a large project) was very difficult for me, but it is a defining moment in my efforts to manage my time. I find that, if you provide an explanation, people are usually very understanding. Unless there is an impending deadline, most people are willing to wait until you are next available. If they are not, they can usually find someone else to assist them and at least you have offered to help. This approach allows me to keep a more realistic diary and to protect the time blocked out for doctorate work.

\section{Issue 3: Lack of Focus}

The need to block out time for important tasks is no doubt obvious to most people. The first two issues discussed above focus largely on managing work-related issues, as I have found these to be the main impediment to me finding time for doctoral study. However, prioritising one's time is only the first task. Ultimately, our effectiveness depends on how we can focus during the times that we allocate to given tasks. Focus, for me, is the crux of the issue, and I have found that three key issues can impact upon this.

\section{Finding a balance}

While effectively managing my work schedule allows me to commit to doctoral study periods, my effectiveness within these study periods is negatively impacted when I don't have an adequate focus on family and my own well-being - notably exercise, healthy eating and downtime. A healthy balance between work, family and self really allows me to focus during doctorate study periods, refreshed and without feelings of anxiety or guilt.

Finding such a balance can be difficult, and doctorates are often only possible with the support of an understanding family. For a long time, I set targets to complete certain doctorate tasks in a given week. However, I didn't link these to specific time slots, rather playing it by ear as to what evenings I felt energetic enough to focus on my doctorate. I now 
agree evenings and weekend morning slots with my wife before the start of the week so that we are clear on family commitments and my availability. This also means that I can enjoy evenings free of doctorate work, allowing me to switch off and not feel guilty.

\section{Finding a productive space}

It usually takes part-time doctoral researchers some time to figure out 'where' they are most productive. Some people manage to block out periods of time while they are in the office, but I find it hard to fight the urge to tackle work tasks or I am interrupted by well-meaning colleagues or students looking for help, advice or a chat. I set up a home office at the outset of my studies, but found that, due to its location in the house, and the arrival of twin sons, it became very cluttered. I simply cannot focus when working in a cluttered space, so my home office was doomed to fail.

Furthermore, some people find it incredibly difficult to work from home, where there are lots of distractions. Stories of doctoral researchers cleaning ovens and doing laundry are all too common. I fell into this trap, convincing myself that I should do household chores while at home. I would advise doctoral students to try working at home for a while before investing in a home office. If you are someone who finds it difficult to concentrate in a cluttered space (I know many people who don't have this problem), try cleaning the house the night before and removing as many distractions as possible. Treat your office as a work space and have a trigger for moving from work mode to family mode, such as closing the office door, showering or some other action that signifies the move to work mode. Ensure your family knows that you won't be available to do household chores until you finish for the day; and if there are others in the house, they need to resist the urge to interrupt you. If this is not possible or the house is simply too busy, you might need to find another location.

I found two very useful places for doctoral work - libraries in other universities (not my place of work) and coffee shops. The library is a great place when high levels of concentration are needed, i.e. when reading, writing and trying to understand difficult concepts. I find the right coffee shop provides a nice change of scenery and works great when searching for or downloading journal articles and for certain types of analysis or writing. I am spending a lot of the latter parts of my doctorate moving between both. I would encourage new doctoral students to simply try a few places and then pick a location which suits them and fits the nature of that day's task. When studying away from home, be 
cognisant of opening/closing times, Wi-Fi availability, access to refreshments, travel time, etc. Most of these things can be checked in advance.

\section{Managing distractions}

The centrality of mobile phones in our daily lives brings a lot of potential distractions. Social media, news apps, email and phone calls are my main distractions. When trying to work on my doctorate, I find that simply putting my phone out of sight and switching on airplane mode works best. However, there are times when work or family commitments preclude me from doing that. Ironically, the 'switching off' (from technology) movement has spawned a whole range of new apps. A colleague told me about some apps that can be quite useful in helping people to focus for set blocks of time, and allowing time in between to do small tasks, for example 25 minutes of dedicated focus and then 5 minutes to check for any calls or to simply use the toilet or grab a coffee. I have found these apps quite useful in instances when I cannot turn off my phone.

During extremely busy work periods, I can find it difficult to focus on my doctorate as thoughts, ideas and concerns continuously pop into my head. In the same way that a notebook by the bed can help people to empty their mind of thoughts before sleeping, I keep a pen and paper beside me when doing doctoral work and simply make a quick note and then refocus. When not working on my doctorate, I use a digital calendar and a tasks app, these can also work well during study periods if you can avoid becoming distracted by them.

\section{Issue 4: Structure and Deadlines}

There are many types of doctoral programmes. I decided to complete a traditional $\mathrm{PhD}$, while many of my colleagues have opted for a structured $\mathrm{PhD}$ or a Doctorate of Business Administration (DBA), which tend to involve firm deadlines for specific outputs.

Including undergraduate and postgraduate studies, I have studied in three universities on both a full-time and part-time basis and I have worked with a number of supervisors. Some universities take a very structured approach, while others do not, and this is also the case for supervisors. As I am someone who needs a lot of structure and clear deadlines, I find that a monthly supervision meeting/call and accompanying report works well for me. Weekly work plans are also great, but a monthly plan with a supervisor is probably enough as if you fall slightly behind one week you can make it up the next week and still meet your 
initial target. In the past, with less regular reporting deadlines, there was less urgency and I made little progress.

I would recommend that doctoral students, part time or full time, think carefully about their choice of programme and commit to monthly updates even if these are not required by their university or supervisor. I would also recommend agreeing a timeframe for completion with one's supervisor and initial targets for individual chapters that can be updated along the way.

\section{LESSONS FOR KEEPING YOUR DOCTORATE ON TRACK}

1. Find a way to effectively manage non-doctorate tasks. Without this, completing will be incredibly difficult, if not impossible.

2. Focus on your priorities and don't be afraid to say 'No' or 'Not now' to other people's requests where required. Also beware of taking ownership of other people's tasks.

3. Along with setting goals, block out weekly time slots for your doctorate, which you agree with family.

4. Set the right conditions so that you can focus during these study periods. Ensure you achieve a balance between work, family and self, find a suitable study location, and manage distractions.

5. Agree monthly deadlines and a monthly work plan with your supervisor.

\section{REFERENCES}

Covey, S.R. (1989). The Seven Habits of Highly Effective People. New York, NY: Simon \& Schuster.

Meredith, J.R., Shafer, S.M. and Mantel, S. (2017). Project Management: A Strategic Managerial Approach, 10th edn. Hoboken, NJ: John Wiley \& Sons Inc.

Oncken, W. and Wass, D.L. (1974). Management Time: Who's Got the Monkey? Harvard Business Review, 52(6), 75-80. 